\title{
UNIVERSUM
}

\section{ENTRE LO PERMITIDO Y LO PROHIBIDO: AZÚCAR Y DESPLIEGUE DE LOS SENTIDOS EN EL BARROCO HISPANOAMERICANO. LAS ALCORZAS DE LAS MONJAS CLARISAS DE SANTIAGO DE CHILE (SIGLOS XVII Y XVIII)}

Between the permitted and the prohibited: sugar and display of the senses in the Spanish American Baroque. The icing of Clarisas nuns of Santiago de Chile (I7th and I8th Centuries)

\section{Isabel Cruz de Amenábar' iD \& Alejandra Fuentes González² (iD}

'Universidad de los Andes, Las Condes, RM, Chile. Profesora e Investigadora. Doctora en Historia del Arte de la Universidad de Navarra.

${ }^{2}$ Universidad de los Andes, Las Condes, RM, Chile. Doctora en Historia

Wuentesgonzalezalejandra@gmail.com

\section{RESUMEN}

El gusto, ubicado tradicionalmente en el último lugar en la escala de los sentidos, adquirió con el uso del azúcar durante el barroco, una valorización que se manifestaba en el auge de la repostería, con efectos incluso en el periférico Reino de Chile. La cultura del azúcar, como producto simbólico de lujo, poder y sensualidad, asociado a la mujer; incluía también a las monjas de clausura, representadas en Santiago por las clarisas antiguas. Sus exquisitos dulces de "alcorza" deleitaban no solo el paladar, sino a través de sus formas, olores y modelados, los cinco sentidos. ¿Cómo se explica la dulcería - fuente de placer multisensorial- en aquellas instituciones donde las religiosas debían mortificar justamente su sensualidad?, ¿por qué esta aparente paradoja?, ¿contravenía el azúcar las reglas monásticas, o más ampliamente, las pautas dietéticas de la época? El presenta artículo demuestra la plena aceptación del azúcar en el Monasterio Antiguo de Santa Clara, a través del recorrido histórico de esta materia prima, así como de la compulsa documental de las crónicas jesuitas y los registros conventuales. Era tal el prestigio del azúcar en este "micromundo", que no solo permitió la coexistencia de estos confites con las prescripciones eclesiásticas, sino que también, una incipiente revalorización del sentido del gusto, previo a las teorías sensualistas del siglo XVIII.

PALABRAS CLAVE: sentido del gusto; azúcar; barroco; monjas; Santiago.

\section{ABSTRACT}

Taste - traditionally located in the last place on the scale of the senses - acquired with the use of sugar during the baroque, a valorization that manifested itself in the rise of pastry, with effects even in the peripheral Kingdom of Chile. The culture of sugar, as a symbolic product of luxury, power and sensuality, associated with women; It also included the closing nuns, represented in Santiago by the ancient poor clares. Its exquisite "alcorza" sweets delighted not only the palate, but through its shapes, smells and modeling, the five senses. How do you explain the candy store - source of multisensory pleasure - in those institutions where the religious women had to mortify their sensuality precisely? why this apparent paradox? did sugar contravene the monastic rules, or more broadly, the dietary patterns of time? The present article demonstrates the full acceptance of sugar in the Old Monastery of Santa Clara, through the historical route of this raw material, as well as the documentary compilation of the Jesuit chronicles and conventual records. Such was the prestige of sugar in this "microworld", which not only allowed the coexistence of these sweetmeats with ecclesiastical prescriptions, but also, an incipient revaluation of the sense of taste, prior to the sensualist theories of the eighteenth century.

KEYWORDS: sense of taste; sugar; baroque; nuns; Santiago.

Fecha de Recepción 2019-1I-26

\section{Fecha de Evaluación}

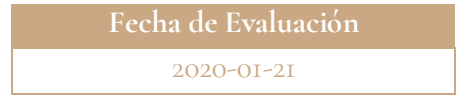

Fecha de Aceptación

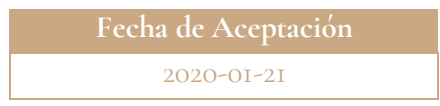




\section{INTRODUCCIÓN}

Los estudios de la cocina colonial chilena han señalado que las monjas impulsaron el profuso desarrollo de la dulcería durante esta época, aunque no se ha realizado una investigación para develar los factores de este fenómeno en particular (Pereira Salas, 1977: 40-44), (Valdés, 1994), (Cruz de Amenábar, 1995), (Cruz de Amenábar, 2003: 87-94); (Montecino, 2005: 20) y (Sciolla, 20io: 163-193). Al respecto, convienen destacar los siguientes: la transferencia del oficio culinario desde los monasterios españoles hacia los cenobios hispanoamericanos, fundados estos últimos por las antiguas órdenes religiosas europeas; la necesidad de agasajar a bienhechores y autoridades para garantizar la subsistencia de las comunidades; la tradición del monacato cristiano primitivo y medieval, a partir de la cual estas religiosas dividían su jornada diaria entre la oración contemplativa y el trabajo manual; y la facilidad con que las monjas obtenían las materias primas necesarias para elaborar estas recetas, como sucedía con el azúcar.

Considerando lo anterior, el presente artículo estudia la elaboración de las alcorzas por parte de las clarisas de Santiago durante los siglos XVII y XVIII — mencionadas por los cronistas de la época y cuyos ingredientes están documentados en su archivo monacal- como un ejemplo del potencial sensorial del azúcar en el reino más austral de la Monarquía Hispánica․ Ubicadas en una posición intermedia entre la antigua ascética cristiana recogida por los moralistas jesuitas, y la exacerbación de los sentidos que caracterizaba la cultura barroca del dulce, estas figuras no solo cautivaban el paladar sino concitaban la vista, el olfato, el tacto e incluso el oído de quienes las fabricaban y disfrutaban². A partir del análisis histórico y estético de este arte culinario, monástico y femenino; se demuestra su despliegue casi sin restricciones y su contribución a la revalorización del gusto, tradicionalmente ubicado en la escala más baja en la jerarquía occidental de los sentidos³.

\footnotetext{
${ }^{1}$ El Monasterio Antiguo de Santa Clara fue fundado en Osorno hacia 1560. Tras la rebelión indígena de fines de siglo, se reinstalaron en Santiago en I605, en los terrenos donde hoy está la Biblioteca Nacional. A principios del siglo XX se trasladaron a Recoleta y a Puente Alto. Por la falta de vocaciones y el terremoto del ${ }_{27} \mathrm{~F}$, este monasterio cerró definitivamente en 2017 .

${ }^{2}$ Los sensaciones de los cuatro sabores básicos del ser humano — amargo, ácido, salado y dulce- son captadas por las papilas gustativas situadas en la lengua. Las señales del gusto, procedentes de los diferentes segmentos de dicho órgano, son recogidas por las fibras nerviosas que llegan a cada uno de los cuatro nervios craneales, encargados de transmitir la información al cerebro. En su mayoría, el sabor dulce se estimula con azúcar o miel (Cruz Cruz, 2002: II9-I26), (Sancho I999: 83 y ss) y (Mintz, 1996: 4I-42).

3 Durante las últimas décadas, los Estudios Sensoriales han impulsado investigaciones históricas y antropológicas sobre los cinco sentidos. En su mayoría, aquellas se han concentrado en uno o dos sentidos específicos, aunque se ha reconocido una intersensorialidad en su funcionamiento (Howes, 2014: I0-26). En Chile, destacan las publicaciones de Catherine Burdick sobre el olfato y el oído en la época colonial (Burdick, 2019: 9I-I22).
} 


\section{DULZURA DEL PALADAR: ORÍGENES Y EXPANSIÓN DE LA CAÑA DE AZÚCAR}

La caña de azúcar (Saccharum officinarum) fue domesticada en Nueva Guinea hacia el 8.ooo a.C., y pasó a Filipinas dos mil años después. Aunque no hay evidencia de su uso cristalizado, se constata su conocimiento en la Antigüedad y su difusión en India y China (Dioscórides, 2007:19o), (García, I989: 2I4-2I5), (Riera Melis, 2014: 40-4I) y (Toussaint-Samat, I987: I6-49). Entre el 633 y el 642 d.C., avanzó al poniente con la conquista islámica del Tigris y el Éufrates, con lo que los musulmanes se atribuyeron el rol difusor del azúcar, además de ampliar su uso médico y productos manufacturados ${ }^{4}$. Apareció en Siria, Palestina y Egipto hacia el 7oo, y en al-Ándalus alrededor del 756 (Riera-Melis, 2003: 22) y (Khune, I992: 4I-62). A partir del siglo X se difundió en Venecia, ciudad que recién fundada construyó depósitos de azúcar para distribuirla junto a la seda y las especias (Toussaint-Samat, I987: 17-33). Prontamente se formaron plantaciones en Chipre, Malta y Sicilia (Mintz, I996: 54-55).

Entre los siglos XII y XV el azúcar se dio a conocer en Europa occidental como un producto de lujo. En aquella época, su significado cultural coincidía con los ideales cristianos, pues la sacarosa más fina tenía que ser de color blanco, estableciéndose así un inusitado parangón entre dicha materia prima y la virtud de la pureza (Mintz, I996: 51). En ello influyó también la consideración de sus propiedades saludables, ya que esta se utilizaba en la preparación de electuarios o letuarios 5 para limpiar el organismo, favorecer la digestión y aplacar inflamaciones. Asiduos a ellos eran las monjas medievales, pues les permitían sobrellevar sus mortificaciones, purificando el cuerpo y el alma. Las indicaciones de Santa Hildegarda de Bingen contribuyeron a su empleo y difusión, como ocurrió con el electuario de galanga o con el de hinojo (Bingen, 20I3: I27-I55).

El prestigio del azúcar en el campo medicinal bajo la forma de electuarios se refrendaba en escritos religiosos medievales que avalaban su uso sin contravenir la ascética cristiana (Sancho, I999: 83). Una obra doctrinal clave y de amplia influencia como la Suma Teológica de Santo Tomás, justificaba su consumo incluso durante los días de ayuno (Aquino, 1994: 436). Esta consideración terapéutica del azúcar estuvo presente desde el primer recetario publicado de cocina española, el Libro de guisado, manjares y potajes (I520) del maestro catalán Ruperto de Nola, que recomendaba a los enfermos la ingesta de bebidas o comidas dulces, apelando a los poderes reconfortantes de esta

\footnotetext{
${ }^{4}$ Este artículo no profundiza en el uso médico del azúcar, abordado específicamente en otro estudio.

5 "Medicamento de consistencia líquida, pastosa o sólida, compuesto de varios ingredientes, casi siempre vegetales y de cierta cantidad de miel, jarabe o azúcar, que en sus composiciones más sencillas tiene la consideración de golosina" (RAE). Esta consideración de "golosina", recoge los imprecisos límites existentes durante la Edad Media y el Barroco entre la farmacopea y la confitería, comprobados en los manuales de principios del siglo XIX (Henry, I830: 4-II6).
} 
materia prima (Nola, 1997: 305-307). Es probable que las órdenes monásticas femeninas de la época hayan conocido este uso médico del azúcar y su consecuente aprobación por parte de los padres de la Iglesia, pues sus diferentes textos normativos —entre ellos, la regla escrita por Santa Clara en I253- dispensaban a las enfermas del ayuno y les permitían consumir alimentos excepcionales a la dieta cotidiana, como pudo haber sucedido con estos dulces medicamentos (Omaecheverría, I993: 258).

\section{LLEGADA DEL AZÚCAR A LOS MONASTERIOS FEMENINOS DE ESPAÑA Y AMÉRICA}

Desde la formación de las Hermanas Pobres de Santa Clara en Asís, a comienzos del siglo XII, se multiplicaron rápidamente en Europa los monasterios de esta orden religiosa femenina. En el caso de España, las nuevas fundaciones sucedieron en plena dominación árabe, cuando el azúcar ya se procesaba en las regiones del levante y del sur de la Península. Allí, la caña de azúcar fue introducida en el reino nazarí de Granada, importada desde Alejandría y luego cultivada por los campesinos en las Vegas de Granada y Motril (Pérez Vidal, 1973). También la plantaban los moriscos en Valencia, en los ingenios de Gandía denominados trapigs o trapiches (Martínez, I989: 20I-202), (Martínez, 1999: 8I) y (Mapelli, 2004: 187). Desplazando lentamente a la miel, esta materia prima pasó desde las oficinas de los boticarios a los talleres de los confiteros, suscitando una revolución semejante a la fraguada en las cocinas por las especias (Faraudo de Saint Germain, I946: 97-I34).

En América, la caña de azúcar, traída por Cristóbal Colón desde Canarias (I493), inició su cultivo en Santo Domingo y desde aquí se embarcó a su vez a Europa, en lo que sería un próspero pero sacrificado comercio basado en mano de obra esclava (Mintz, 1996: 63-64) y (Ritchie, I98I: I55159). La planta progresó deprisa en el resto del Caribe, en México, Paraguay y la costa pacífica de Sudamérica (Mintz, 1996: 64). Aunque en el siglo XVII, España había perdido la energía productiva en el Caribe, donde franceses e ingleses tomaban la delantera, la caña de azúcar circulaba de norte a sur, pero su consumo seguía restringido a una minoría que lo usaba con fines medicinales, decorativos y de ostentación (Mintz, I996: 78). Fue en el siglo XVIII y principalmente en el XIX, cuando el consumo de este producto se amplió en la población. En Chile ocurrió un proceso similar, pues no fue posible implantar ingenios de azúcar durante la época colonial (de Ramón y Larraín, 1982: 156). Tuvo que ser importado en principio desde Perú, lo que sumado al alto precio que adquirió en la primera mitad del siglo XVII implicó que su introducción en la cocina chilena 
fuese gradual (Pereira Salas, 1977: 26). Su consumo aumentó significativamente desde el siglo XVIII, cuando comenzó a ser traído también desde Cuba y Buenos Aires (de Ramón y Larraín, I982: I6I162).

La expansión de la caña de azúcar enriqueció y difundió la repostería en los virreinatos americanos y en particular en el del Perú, y lo que en la Edad Media eran delicias y excentricidades gastronómicas propias de las cortes, se replicó aquí en los círculos de virreyes, gobernadores y élites de la región surandina. En este proceso los monasterios de mujeres fueron esenciales, tanto en el traslado de los productos como en la elaboración de estos al otro lado del Atlántico, constituyéndose, como en Europa, un vínculo innegable entre el mundo femenino y el del azúcar (Zolla, 1988: III). Las criadas moriscas, que tan importante y poco estudiado rol jugaron en el desarrollo de las manualidades en los conventos hispanoamericanos, fueron las que introdujeron en las mesas señoriales la amplísima variedad de preparaciones de tradición árabe, entre otros: dulces de frutas, confituras, mermeladas, jaleas y conservas, almendrados, garrapiñados, pastas de yemas, bizcochos, hojaldres, alfajores, turrones, arroz con leche, aguas perfumadas, jarabes y sorbetes ${ }^{6}$.

En los monasterios femeninos de Santiago de Chile, el azúcar jugaba un papel clave en la vinculación con la élite extramuros, pues las religiosas elaboraban dulces para agasajar a sus autoridades y bienhechores en los periodos festivos, por ejemplo, en Pascua de Resurrección, en Navidad y en las celebraciones dedicadas a San Francisco, Santa Clara, Santa Teresa y Santa Rosa de Lima. La manufactura estaba dirigida por las monjas de velo negro, descendientes de los primeros conquistadores del Reino, e incorporaba la colaboración de monjas de velo blanco, novicias, donadas, criadas y esclavas. Al igual que otros productos fabricados por las monjas coloniales, como sucedió con la cerámica perfumada de las clarisas antiguas; la repostería de estas comunidades fue resultado de un trabajo colaborativo entre profesas y seglares. Así se explica el carácter mestizo de estos platillos con azúcar y su importancia en el entorno más próximo. Uno de estos dulces agasajos, característicos del primer monasterio de clarisas fundado en Chile, fueron las llamadas alcorzas.

\footnotetext{
${ }^{6}$ La presencia morisca en América ha sido abordada en las últimas décadas (Taboada, 2004: I15-I32), (Cáceres, 2005: 565574), (Mujica, 2007: 169-I79) y (Cook, 2016). Para Chile, se consignan mujeres moriscas en Concepción hacia I550 que pudieron trasladarse a Osorno e integrar el monasterio clariano (Cano, I98I: 125) y (Vial, I957: 17).
} 


\section{LAS CLARISAS DE SANTIAGO Y EL DELEITE SENSORIAL DE SUS} ALCORZAS

Las alcorzas, según los diccionarios españoles de los siglos XVII y XVIII, eran pastas o "costras" de azúcar blanca y refinada con las cuales se cubrían o modelaban diferentes tipos de dulces. De origen árabe, se esculpían con ellas diversas figuras: aleluyas, flores, ramos "y otras cosas con mucho primor y artificio" (Covarrubias, I647: 28) y (RAE, I726: 185). Describieron las alcorzas elaboradas por las monjas clarisas de Santiago, los cronistas jesuitas Alonso de Ovalle y Diego de Rosales, como verdaderas escenografías de azúcar multicolor, de formas naturalistas, desplegadas en las iglesias, entre los altares y sobre las mesas civiles, cuyo efecto gustativo - táctil, visual y consumido por fieles y comensales - se potenciaba con el deleite olfativo de perfumes, resinas e incienso humeantes, y el sonido de las aguas rociadas sobre los pisos sembrados de pétalos. Para Ovalle, estas religiosas destacaban singularmente por aderezar sus iglesias con estos dulces ornamentos:

La curiosidad, limpieza, y riqueza de los altares; y ornamentos sacros, no puede mejorarse; que diré de los olores, flores artificiales, pomas, cazoletas, pebetes, y pebeteros, he visto estos algunas veces en la capilla mayor tan grandes y hermosos, que admiran por la materia de que los hacen, que es de azúcar blanco como la nieve, ya en forma de castillo, ya de candelero, o pirámide, todo de admirable, y exquisita manifatura. (Ovalle, 1646: 165).

Enfatizaba el cronista la importancia de tales decoraciones en las festividades religiosas y en las fiestas de matrimonios y bautismos, donde engalanaban mesas, altares y procesiones (Ovalle, i646: 165 y i70). Allí, el azúcar excedía su naturaleza al decorarse nada menos que con oro y plata evocando un proceso de alquimia- modelándose en forma de soles, ángeles, serafines, frutas, alhajas, aves, peces, aguamaniles, jarros, tazas, alcarrazas, saleros, platos, cuchillos, cucharas y tenedores. Según el jesuita, estas figuras eran tan perfectas y delicadas, que estimulaban el sentido de la vista de quienes "más habían visto" (Ovalle, i646: I7o).

Unas décadas más tarde, Rosales describía en el ámbito civil, el suntuoso banquete que ofreció la ciudad al gobernador entrante del Reino de Chile en r646, Martín de Mujica y Buitrón; cuyas frutas y figuritas "contrahechas" de azúcar engañaron graciosamente, en una práctica muy barroca, su ojo y su apetito:

Al gobernador don Martin de Moxica le aconteció ir a desdoblar la servilleta, sentándose a comer en el primer recevimiento que le hizo esta ciudad de Santiago, y hallarla de alcorza tan al vivo que sus dobleses y disposicion le enganaron, pareciéndole que era servilleta alemanisca, sucediéndole lo mismo con el cuchillo, con el pan y las aves que se le sirvieron, y assi mismo con las frutas y las limas, que queriendo esprimir una que estaba cortada en un plato que se le puso sobre una ave, se halló engañado, por ser la lima de alcorza. (Rosales, I877: 390-391). 
Un trompe l'oeil o trampantojo que en el barroco fue tan frecuente en la pintura, con efectos como "el cuadro dentro del cuadro", el marco simulado, el "rompimiento de gloria"; solo que en este caso y en otros que se registran en la historia de la repostería, las escenografías eran de azúcar y estaban destinadas a ser consumidas.

La cultura del azúcar, de lejana herencia árabe y oriental, pone sobre las pistas del extraordinario uso decorativo, artístico y sensorial de esta materia prima, que descansaba en un triple sustrato: la relación simbólica entre el color blanco —el que se obtenía a partir de dificultosas técnicas de refinación-y la pureza; en las propiedades conservantes y terapéuticas de este azúcar clarificado y su extraordinaria plasticidad para adoptar diferentes estados, formas, texturas y colores; y la facilidad con la que otros productos comestibles podían combinarse con el azúcar en resultados sólidos o líquidos (Mintz, 1996: I25-I27).

En las cortes musulmanas, la estética de la mesa se asemejaba al trabajo de orfebres y joyeros, tan significativo en el arte cristiano, ya que su religión impedía a los adeptos comer en vajilla de oro y plata, pero esta podía ser imitada en cerámica, e incluso en azúcar. Por ello, sus cocineros empleaban azafrán para dorar comidas, azúcar para imitar los diamantes, y carne en rodajas para reproducir monedas de oro y plata; además de elaborar platos con figuras de cornalinas y perlas (Fernández-Armesto, 2019: I88). El califa del siglo XI, al-Zahir, habría celebrado las festividades islámicas con "obras de arte de los confiteros", incluyendo cientos de figuras de azúcar. Asimismo, Nasiri-i-Chosrau, un visitante persa que viajó a Egipto en I040 —donde se cultivaba y procesa el azúcar a gran escala- reportaba que había visto en la mesa del sultán para el Ramadán, un árbol de azúcar y otros enormes adornos fabricados con este producto (Mintz, I996: 126-I27).

Desde el siglo XIII, la costumbre de utilizar azúcar como decoración se extendió desde el norte de África hacia Europa y las cortes medievales de Francia, Inglaterra, Italia y España (Ritchie, I981: 93-94). Estos adornos o "sutilezas" tenían formas humanas, de animales, objetos, edificios y seres mitológicos y, puesto que el azúcar era caro y difícil de obtener, eran muy admirados y consumidos por los reyes, la nobleza, los caballeros y la Iglesia en sus diferentes celebraciones. Así, por ejemplo, en la coronación de Enrique IV de Inglaterra (1399), se exhibió una curiosa figura de azúcar que representaba al nuevo rey escoltado por San Luis y San Eduardo (Ritchie, I98I: 94) y (Mintz, 1996: 128). En I413, para la coronación de su sucesor, Enrique V, se modeló una figura de cisne con la frase "Mira al rey, y verás la estampa de la honradez" (Ritchie, I981: 94). Las cortes italianas también destacaron en esta práctica culinaria y social, especialmente la de la familia 
Visconti-Sforza. Para la visita de Enrique III de Francia, se elaboraron diversas "sutilezas" en forma de pan, platos, cuchillos, tenedores, manteles, servilletas y diversos ornamentos como las que casi un siglo más tarde recibirían al otro lado del mar y del mundo a Martín de Mujica en el lejano Chile, como señala el padre Rosales; en total, i286 obras de arte realizadas por Nicolo delle Cavalliera con los modelos diseñados por el escultor y orfebre Jacopo d'Antonio Tatti Sansovino, que muestran los alcances del azúcar para el siglo XVII (Toussaint-Samat, 1987: 34-35).

Aunque en principio la tradición árabe había advertido que en estas figuras el azúcar debía mantenerse de color blanco, con el objetivo de realzar la calidad y pureza de este exótico y lujoso producto, pronto comenzaron a surgir prácticas culinarias y decorativas similares, basadas en la elaboración de diversas pastas que resultaban de la combinación del azúcar con otras materias primas: frutos secos, arroz, aguas perfumadas, resinas y gomas de origen vegetal, entre otros. Sucedió, por ejemplo, con el mazapán, preparación de azúcar y aceite de almendra originaria del Medio Oriente y difundida en Europa desde el siglo XII en adelante (Mintz, 1996: 126).

Las clarisas de Santiago de los siglos XVII y XVIII, confeccionaban estas figuras a partir de una pasta similar a la arcilla, suficientemente maleable para esculpir diversas formas a distintas escalas. El ingrediente principal era el azúcar refinado, importado desde Lima en forma de "panes" (azúcar entera) o gránulos (azúcar molida), según registran los libros de cuentas de los archivos clarianos ${ }^{7}$. En algunos casos combinaban este azúcar con almendras ${ }^{8}$, sintetizando así la antigua tradición árabe de las alcorzas con recetas posteriores como la del mazapán?. Las religiosas, de acuerdo a las observaciones de Ovalle y Rosales, realizaban tanto figuras blancas como de colores, para lo cual utilizaban diferentes tipos de pigmentos según los objetos que deseaban reproducir; policromía que también podía incluir aplicaciones de oro y plata, por ejemplo, en el caso de vasijas, cucharas y serafines $^{\text {Io }}$. Para deleitar, asimismo, el sentido del olfato, se incorporaban especias como canela, clavo de olor, almizcle y anís ${ }^{\text {II }}$ Tan perfectas eran estas piezas de azúcar, especialmente las de color, que inclusive resultaba difícil distinguir entre la realidad y su representación culinaria y decorativa, como le sucedió a Mujica en el siglo XVII con las frutas y la vajilla de su banquete.

\footnotetext{
7 Archivo del Monasterio Antiguo de Santa Clara (en adelante MCAF), Vol. 57, s.fj. fts. 23 y 40; MCAF, Vol. 6o, fjs. I43-I44.

${ }^{8}$ MCAF, Vol. 52, fjs. 24v y i72v; MCAF, Vol. 54, fj. 48v; MCAF, Vol. 6I, fjs. $95 \mathrm{v} \mathrm{y} \mathrm{I75v}$

9 Según la crónica de Carlos Peña, todavía a comienzos del siglo XX, las monjas de Santiago elaboraban figuritas de azúcar y pasta de almendra (Peña, 1951: 104-IO5).

1o El archivo de las clarisas constata la adquisición de sustancias para elaborar pigmentos: achiote, grana cochinilla, polvo de juanes, hematite, cinabrio, añil, piedra lipe, azafrán, libritos de oro y plata, etc. Estos últimos, eran utilizados también para teñir textiles y cerámicas (Cruz, 2019: IOO-Iı).

${ }^{11}$ El Monasterio Antiguo de Santa Clara compraba constantemente estas especias, según demuestra su archivo conventual. Canela: MCAF, Vol. I04, s.fj., ft. 217; MCAF, Vol. 54, fj. 68v; MCAF, Vol. 6r, fj. 6v; MCAF, Vol. 6r, fj. 293. Clavo de olor: MCAF, Vol. I04, s.fj., ft. 217; MCAF, Vol. 57, s.fj., ft. 40; MCAF, Vol. 6r, fj. 6v, 7, 49-53v, I30-I33 y 293. Almizcle: MCAF, Vol. 6r, fj. 6v, r30-I33 y 293. Anís: MCAF. Vol. 52, fj. 202v; MCAF, Vol. 6o, fj. 298v.
} 
Es muy probable que las clarisas chilenas hayan conocido el proceso de elaboración de estas figuras culinarias y estéticas a partir de los recetarios que circularon en la Península Ibérica desde fines de la Edad Media. Por ejemplo, el Vergel de señores en el qual se muestra a hacer con mucha excelencia todas las conservas, electuarios, confituras, turrones y otras cosas de açucar y miel, manuscrito redactado hacia el siglo XVI (Pérez Samper, 20I2: 29), difundía recetas tanto para confeccionar alcorzas como para preparar mazapanes de distintos tipos ${ }^{12}$. La elaboración de las alcorzas incluía azúcar, agua rosada y almizcle, y se utilizaban moldes untados con aceite de almendra para esculpir sus formas (Vergel: 6o-6r). Este compendio incluía también fórmulas para colorear el azúcar, salplicarlo de dorado y plateado, y recetas para elaborar figuras de mazapán con azúcar y almendras molidas (Vergel: 6I-65). Por esta época, las alcorzas y los mazapanes fueron incluidos, entre otros, en el Regalo de la Vida Humana de Juan Valles, en Los cuatro libros del arte de confitería de Miguel de Baeza, publicado en Alcalá de Henares en 1592, y en los recetarios catalanes del gremio de los confiteros como el de Francesc Corominas, de I663 (Pérez Samper, 20I2: 34). Igualmente, fueron considerados en el Manual de mujeres en el cual se contienen muchas y diversas recetas muy buenas, manuscrito español del género de los recetarios femeninos de fines del siglo XV y principios del siglo XVI, donde no solo se daban recetas de cocina sino de remedios, higiene e incluso belleza. Las instrucciones para hacer alcorzas señalaban:

Moler el azúcar y pasar por cedazo. Y después de pasada por el cedazo, echarla en un almirez limpio. Deshacer un poco de ámbar y almizcle en agua de azahar y deshacer el azúcar con aquella agua, echándole poco a poco el agua. Y después que esté hecha la masa de azúcar, hacer las alcorzas y cocerlas. (Crespo, 1995: 7I).

Los mazapanes, por su parte, se elaboraban con azúcar molido y almendras machadas, ingredientes que primero se amasaban con agua rosada y que luego se cocían al horno (Crespo, 1995: 86).

Ya para el siglo XVIII, el Arte de Repostería, en que se contiene todo genero de hacer dulces secos, y en líquido, vizcochos, turrones, $y$ natas, publicado en 1747 por Juan de la Mata, que se conoció en Chile, indicaba el modo de hacer alcorzas —denominadas para entonces, "figuras de azúcar"- y mazapanes, a partir de métodos similares a los del Vergel y el Manual de mujeres. Para las alcorzas, se consideraban recetas de huevos y aceitunas "artificiales" (Mata, I747: 137), mientras las recetas de los mazapanes incluían: mazapán común, "de horno a la española muy puesto en uso", real, ligero, de alfónsigos, de chocolate, de flor de naranja, de limón, "frambuesado", "bañado" y "forrado" (Mata, I747: IOI-IO8). Asimismo, consideraba instrucciones para dar color: el rojo se conseguía mezclando

\footnotetext{
${ }^{12}$ Esta datación difiere de la realizada por Simón, quien sitúa su redacción en el siglo XV (Simón, 2010: 63)
} 
grana cochinilla, crémor de tártaro y alumbre; el verde con cáscaras de peras y acelgas; el amarillo con flores de azucenas, avellanas y agua de azahar; el azul con flores del mismo color; y el negro con los frutos del álamo (Mata, I747: 76-78). Inclusive, este repostero leonés establecido en Madrid, especificaba el modo de organizar las figuras de azúcar y los mazapanes en la mesa, dependiendo del número de comensales (Mata, I747: s/p).

\section{DESPLIEGUE Y CONTROL DE LOS SENTIDOS EN LA CULTURA BARROCA DEL DULCE}

Este lujoso despliegue de azúcar en las clarisas chilenas, una orden con estricto voto de pobreza, sería difícil de imaginar si no estuviese documentado, y de no existir el actual testimonio de la repostería monástica en España e Hispanoamérica, donde las monjas son las depositarias de esta tradición confitera.

En la regla de Santa Clara (I253), el gusto estaba limitado por el ayuno constante, exceptuando los domingos, la Natividad del Señor y los "tiempos de manifiesta necesidad". Como se ha señalado, no estaban sujetas a esta penitencia las hermanas enfermas o las novicias (Omaecheverría, 1993: 258). Las constituciones franciscanas señalaban además que se debía comer "en tierra", es decir, en vajilla de cerámica o barro (Constituciones generales, i639: 58). Sin embargo, no había una restricción específica a la preparación o a la degustación de dulces, de ahí que estos pudieran confeccionarse sin trabas y por siglos - hasta la década de 1980 con sus miniaturas todavía salpicadas de oro y plata- al interior del claustro de la Alameda y después en Recoleta y Puente Alto.

Contra lo que pudiere conjeturarse, la jerarquía eclesiástica de los siglos XVII y XVIII tampoco hizo cuestión de este asunto, por ser el azúcar todavía considerado un producto medicinal y, sobre todo, porque sus miembros estaban entre los beneficiarios de estos dulces agasajos en sus visitas de cortesía o de control a los monasterios. Pese a las constantes alusiones al recogimiento de las esposas de Cristo $^{\text {I3 }}$, los prelados dieciochescos se limitaron a organizar - pero sin vetar- la costumbre de agasajar con suntuosos almuerzos a confesores y sacerdotes, los que incluían refrescos y bebidas estimulantes como el mate, el chocolate y la aloja de culén ${ }^{14}$. Durante el siglo XIX se buscó regular, además, la frecuencia en el consumo de mate, té y café por parte de las religiosas; la austeridad en la alimentación en general, excluyendo el caso de las enfermas que podían ingerir

\footnotetext{
${ }^{13}$ Como ejemplo constan las disposiciones del obispo Luis Romero, de septiembre de 1708. MCAF, Vol. 9I, fjs. 4-6v. ${ }^{14}$ Lo señaló Gregorio Tapia en i76o y también Manuel Vicuña en I842. MCAF, Vol. 91, s.fj., ft. IO3; MCAF, Vol. 9I, s.fj., ft. 185 .
} 
platillos de mejor calidad; la tenencia y almacenamiento de comida al interior de las celdas; y la venta de conservas en las fiestas religiosas ${ }^{15}$.

La inexistencia de una normativa episcopal clara y precisa en torno al desarrollo de la dulcería en los claustros femeninos de Chile, al menos durante los siglos XVII y XVIII, podría estar relacionada pues con el uso médico del azúcar. En noviembre de I77I, por ejemplo, el Monasterio Antiguo gastó seis reales en "frutas para dulce de las enfermas", y en septiembre de i789, desembolsó un peso por este mismo motivo ${ }^{16}$. En 1820 se gastaron catorce y medio reales para comprar una caja de guindas "para dulce del año siguiente, así para la enfermería como para cumplidos del convento"; mientras que un mes después se compraron cuatro arrobas de azúcar molida para sorbetes dulces y otros usos de las enfermas ${ }^{17}$. Al respecto, es primordial señalar que la "dulcificación" de la sangre había sido recomendada por el Protomedicato para combatir la viruela, lo mismo que las aves, la leche y los huevos; ingredientes que también estaban presentes en las recetas con azúcar que preparaban las monjas (Caffarena, 2016: 85).

No obstante, desde la Metrópoli llegaba el eco de los moralistas jesuitas del siglo XVII, quienes consideraban al gusto, en razón de la desmesura y el desorden del pecado de la gula, el sentido que más acercaba al hombre al bruto. Referían expresamente a su moderación, Lorenzo Ortiz y Diego Calleja, siguiendo la tradición clásica aristotélica y la ascética cristiana de los padres de la Iglesia. En sus escritos, ambos autores remitían a aquella consideración de los sentidos como mediadores entre el cuerpo y el entorno, capaces de conducir al ser humano al pecado y, al mismo tiempo, al cultivo de las virtudes (Ortiz, I678) y (Calleja, I7oo). El sentido del gusto, según Ortiz, era uno de los cinco instrumentos que había entregado Dios a los hombres para que estos comprendiesen el mundo, pero los emparentaba con los animales si su práctica conducía al vicio (Ortiz, I678: 178-295). Calleja, en tanto, recomendaba el ayuno para evitar no solo la gula, sino ira, lascivia, avaricia, envidia, soberbia y pereza (Calleja, I70o: 237). Asimismo, aconsejaba algunas privaciones moderadas en la comida, relacionadas principalmente con el exceso - "cebo de los vicios"-, y el uso de costosos aderezos y decoraciones que la volvían apetitosa a la vista (Calleja, I700: 250 y 265). No escapaba el azúcar y sus elaboradas preparaciones a la recriminación del preceptista, quien anotaba no sin ironía:

\footnotetext{
${ }_{15}$ Así lo indicaba Manuel Parreño en I863, Rafael Valdivieso en i868 y Jorge Montes en i889. MCAF, Vol. 94, s.fj., ft. 8; MCAF, Vol. 93, fj. 19; MCAF, Vol. 93, fj. 43v.

${ }^{16}$ MCAF, Vol. 6r, fj. I66v; MCAF, Vol. 64, fj. Iv.

${ }^{17}$ MCAF, Vol. 66, s.fj., ft. 163; MCAF, Vol. 66, s.fj., ft. I46.
} 
No se contentó el apetito con la dulzura de la miel pareciéndole que era muy fácil [...] y trazó los ingenios de azúcar donde el precio de los materiales, la muchedumbre de los artificios y solicitud de cuidados es indecible [...] con la costa a la vanidad de sus deleites. (Calleja, I700: 250).

El cristianismo, no obstante, ha rescatado desde sus orígenes el valor positivo del alimento, del cual el pan eucarístico del banquete es el ejemplo paradigmático y, desde que el azúcar se expande en Occidente, la mística ha buscado la metáfora del sabor dulce para referir las experiencias del alma: "dulcísimo Jesús", "Virgen María, dulzura y esperanza nuestra", son frecuentemente expresiones usadas; y títulos de libros existentes en Chile en el siglo XVIII referían, por ejemplo, a Delicias de la religión o Finezas de Jesús Sacramentado (Cruz, 1989: 176). Lo dulce tenía así una connotación positiva de ternura, consuelo, deleite, reposo y libertad (Bayardo, 2008: 99) y (Rubial, 2011: 153-154). En cambio, lo amargo poseía una carga negativa de contrariedad, dolor y sufrimiento.

Los peligros que acechaban al gusto señalados por Ortiz y Calleja, cuando se producían los extravíos y el desorden de este sentido, mostraban la tradicional jerarquización de la filosofía occidental sobre los cinco sentidos, desde los griegos hasta el barroco, donde el gusto y el tacto ocupaban los últimos lugares (Korsmeyer, 2002: 27-6I). No obstante, ambos tratadistas, aunque abordaban los cinco sentidos por separado, establecieron - especialmente Calleja- numerosos vínculos entre uno y otro (Calleja, I700: IO-268).

El tema de la exaltación de los sentidos, que provocaban entre otros medios, la cocina y las preparaciones con azúcar, no solo fue objeto de la moral o de la culinaria sino también del arte. La pintura barroca, con sus numerosos cuadros y ciclos sobre los sentidos, prueba hoy que el aumento de los bienes de consumo y de productos agrícolas como de manufacturas, trajo una reorganización de la experiencia sensible (Schneider, 2003: 65). Las célebres variaciones sobre el tema de los cinco sentidos de Jan Brueghel el Viejo en el Museo del Prado de Madrid, muestran en ámbitos abigarrados y con gran despliegue formal, las posibilidades de ejercitamiento de cada uno. Los cuadros de Brueghel alegorizan cada sentido como una mujer semidesnuda con los pechos descubiertos, salvo la vista, subrayando el componente erótico de la experiencia sensorial (Schneider, 2003: 66-67). En el sentido del gusto, el artista muestra un primer plano rebosante de viandas de mar y tierra, detrás una mesa ricamente servida y, al lado izquierdo del espectador, una mesita con una bandeja repleta de postres y dulces, y un sátiro, signo de sexualidad, le sirve vino de una jarra a la mujer cuya mano aproxima el bocado pronto a saborear.

Los cinco sentidos no se abordaron solo en la pintura sino en el grabado, como ocurre, entre otras representaciones, en la serie flamenca dibujada por Martin de Vos y grabada por Adrien 
Collaert. La alegoría del gusto se presenta aquí como una mujer rodeada de frutas y hortalizas junto a un manzano, y dispuesta a consumir su fruto - representativo de exquisitez y pecado- mientras a sus pies se sitúa un mono, animal inferior asociado al gusto desde la Edad Media, puesto que se le consideraba provisto de una sensibilidad gustativa más desarrollada que la del hombre y a su constante y reprensible afición a llevarse a la boca todo tipo de alimentos (López, 1998: 321).

\section{LA BLANCA TRANSPARENCIA DEL AZÚCAR: CONFITES, POSTRES Y REPRESENTACIÓN PICTÓRICA}

Las naturalezas muertas pintadas después de esta serie corresponderían dentro de la separación de cada sentido, a una especialización del gusto, en que las connotaciones negativas han sido mitigadas por su valor artístico, simbólico y religioso. En la percepción del espectador, en cambio, entra en juego una integración sensorial, pues sus recursos plásticos permiten representar el sabor dulce "a lo vivo", como muestran los bodegones de los Países Bajos y España durante siglo XVII, que destacan una gran variedad de confites, frutas escarchadas, pasteles, galletas, biscochos y mermeladas.

El azúcar refinado, blanco o transparente, en pastas como las de las alcorzas o en el almíbar denominado "azúcar de hielo", sedujo a pintores flamencos como Georg Flegel, que lo exhibe en su óleo "Pan y dulces" (Stadelsches Kunstintitut de Frankfort). El simbolismo religioso se hace presente allí en la etérea y por tanto espiritual consistencia de sus manjares — higos y frutas confitadas y escarchadas- y en el diseño de dos letras de azúcar, el Alfa y el Omega, principio y fin, que correponden a la ontología de Dios. Forma de cruz adquiere una barra de pan dulce sobre la que se cruza un cilindro de azúcar y una abeja; el bizcocho tiene forma de corazón, la copa de fino cristal lleva vino blanco y junto a la mariposa, son emblemas cristológicos de ofrenda, resurrección y eternidad.

En Flegel el azúcar alcanza una valoración religiosa, como en la Edad Media, cargado de alusiones sacras que remitían a la dulzura del espíritu (Schneider, 2003: 89). Su transfiguración espiritual contrastaba con las voces detractoras que posteriormente alertaron sobre sus efectos adictivos comparándolo a la lujuria; y que en los siglos XVIII y XIX formaban una corriente organizada. Los riesgos del azúcar eran advertidos en obras de este y otros pintores mediante la introducción de simbologías negativas - animales como el ratón, las cucarachas, moscas y gusanos- en las composiciones de frutas y postres, donde la pintura se transformaba en el 
escenario de una lucha entre el bien y el mal, el dulzor y la amargura, aproximándose al género de las vanitas (Schneider, 2003: 90).

En España fue el bodegonista Jan van de Hamen, quien se vio particularmente seducido por la pintura de golosinas y pasteles, donde estos objetos, sin intervención de señales disruptoras salvo moscas, reposaban sus brillos, texturas, transparencias y espesores ordenada $\mathrm{y}$ primorosamente. Así lo atestiguan sus telas en el Museo del Prado y en el Museo Thysen Bornemisza. Otros pintores como Tomás de Yepes, Juan de Espinoza, Pedro Comprobín y Josefa de Obidos, trabajaron también bodegones con dulces en España y Portugal. La variedad de dulces y delicias de azúcar de los bodegonistas del barroco meridional superó a la de los flamencos. Los alimentos azucarados se representan frecuentemente en estas obras junto a búcaros o "barros", evidenciando la relación entre los dulces y la bebida, pues lo empalagoso pedía líquido y especialmente agua fresca como la que contenían estas cerámicas. El vínculo de utilidad entre ambas artes, la repostería y la alfarería, no solo se aunaba en su relación estética sino en la misma práctica, pues, las clarisas de antigua fundación de Santiago compartían su labor entre la dulcería y la cerámica (Fuentes, 2018: 266-290) y (Cruz, 2019: 85-Іі8). Ambas, además de artes del gusto para su consumo, eran de tacto en su ejecución. Las mismas manos se afanaban amasando y modelando, decorando y cociendo locitas y confites.

En la pintura virreinal surandina, la representación de naturalezas muertas con dulces no ocupa un género particular sino se introduce en las obras religiosas, como ocurre con la serie de la vida de San Francisco del Museo Colonial de Santiago, pintada en Cuzco por Basilio de Santa Cruz y Juan Zapaca Inga entre I668 y i684. Cuadros como "San Francisco niño reparte pan a los pobres", "El capítulo de las esteras", "El milagro de las manzanas" y "Santa María de los Ángeles aparece en llamas"; despliegan una lujosa vajilla de plata local y rojos búcaros de barro, frutas, pasteles y dulces (García-Atance, 2002: 4I, 73, 75 у IO7).

Tal como lo enfocaban los textos de los moralistas como el padre Ortiz o Callejas y lo representaron las pintura de Brueghel, la serie grabada de Vos y Collaert y los bodegones de dulces referidos específicamente al gusto, cada órgano es mostrado por separado, segmentando la experiencia de la persona, sin duda con un fin moralizante y didáctico. No obstante, percepciones como las gustativas, a través del enriquecimiento de la cocina barroca y su repostería con la difusión del azúcar, contribuyeron a concertar los sentidos en la cultura y en el pensamiento de la época. Al afinarse la percepción gustativa, se afirmó también la experiencia sensorial como fuente de conocimiento en el empirismo filosófico de John Locke, por ejemplo, encontrando un desarrollo 
específico en el Tratado de las sensaciones (1754) de Étienne de Condillac. Más allá de las enseñanzas del maestro inglés, Condillac se propuso demostrar que únicamente de la sensación, mediante transformaciones y desarrollos, nacía toda la vida cognitiva y psíquica del hombre (Reale, i995: 508). El intenso sensualismo y el gran refinamiento de la cocina del siglo XVIII, especialmente en Francia, con el chef artista Antonin Carêm, quien consideraba la masa como parte de la arquiectura, y el estudio de Brillant-Savarin, Fisiología del gusto (I825) rescataron el gusto, para otorgarle un estatus cultural refrendado por la filosofia kantiana al erigirse en la Crítica del Juicio (I790) como supremo criterio de valor estético (Korsmeyer 2002: 86-88 y i7o).

\section{CONCLUSIONES}

Época de paradojas y contrates, el barroco tensaba en su polaridad el consumo del azúcar. Si los moralistas promovían prácticas ascéticas de ayuno y abstinencia; en festines y banquetes se prodigaba su disfrute. Los sentidos, especialmente el gusto, oscilaron entre extremos, inhibidos por la abstinencia del dulce o estimulados por su exagerado deleite. En la práctica, la moderación y el exceso de alimentos dulces, flexibilizaban sus límites y desplazaron sus fronteras siguiendo la gran expansión geográfica y comercial de un producto cuyos positivos efectos dietéticos y estéticos estaban entonces fuera de duda.

Las alcorzas confeccionadas por las clarisas de antigua fundación durante los siglos XVII y XVIII, se situaban justamente en este contexto de expansión y disfrute del azúcar. La moderación e incluso la privación asociada al alimento en una orden femenina mendicante como las clarisas, coexistían respecto del azúcar, con su despliegue y opulencia en agasajos, fiestas y celebraciones. Las dulces de pastas de alcorza, dispuestos por las religiosas en figuras y barrocas escenografías que convocaban junto al sabor, formas y colores, texturas, fragancias e incluso sonidos; no constituían pues una elaboración aislada ni un caso particular en el uso sensorial del azúcar dentro de la tradición árabe y del barroco hispanoamericano, este último, profundamente imbuido de la herencia cristiana. Transculturada desde España a América y desde el Perú al Reino de Chile, el consumo del azúcar se insertó en una red de circulación global, de la cual Chile no se vio excluido y que en los monasterios femeninos mostraba la singular asociación entre el azúcar y la mujer. Los alcances médicos, culinarios y religiosos de este producto, e incluso su proyección artística y simbólica, demuestran cómo un cultivo, un sabor, una elaboración del ingenio humano, pudo generar aquel conjunto de códigos y creaciones denominado "la cultura del azúcar". 


\section{RECONOCIMIENTOS}

Este artículo corresponde al Fondo Nacional de Desarrollo Cultural y las Artes (FONDART) № 455618: "Una dulce tradición: Investigación de la repostería monástica femenina de Santiago de Chile (siglos XVII-XXI)", financiado por el Ministerio de las Culturas, las Artes y el Patrimonio (2018).

\section{REFERENCIAS}

Archivo del Monasterio Antiguo de Santa Clara (MCAF), Vols. 52, 54, 57, 6o, 6I, 64, 66, 9I, 93, 94, IO4.

Aquino, S. T. (1994), Suma de Teología, Vol. IV, Parte II-II(b). Madrid: BAC.

Bayardo, L. (2008). Sentidos e Ilustración. El cuerpo, los sentidos y el espacio sagrado en el catolicismo. Nueva España 1771-1823. Tesis de maestría en Historia, UNAM, México.

Binguen, H. (2013). Libro de las causas y remedios de las enfermedades. Traducido del Liber Causae et Curae por José María Puyol y Pablo Kurt Rettschlag. Madrid: AKRON.

Burdick, C.; Bieletto-Bueno, N. (2019). Los sentidos en las artes y sonidos de Chile. Usos del olfato y la escucha para una rescritura de la colonialidad. Pasado abierto (9), 9I-I22.

Cáceres, J. (2005). La mujer morisca en el Perú del siglo XVI. Sharq-al-Andalus (I2), 565-574).

Caffarena, P. (2016). Viruela y vacuna. Difusión y circulación de una práctica médica. Chile en el contexto hispanoamericano, 1780-1830. Santiago: Universitaria.

Cano, I. (198I). Las mujeres en el reyno de Chile. Santiago: Ilustre Municipalidad de Santiago.

Calleja, D. (17oo). Talentos logrados, en el buen uso de los cinco sentidos. Madrid: Impreso por Juan García.

Cook, K. (2016). Forbidden Passages. Muslims and Moriscos in Colonial Spanish America. EE. UU: University of Pennsylvania Press.

Covarrubias, S. (1674). Parte primera del Tesoro de la lengua castellana o española. Madrid: por Melchor Sánchez.

Crespo, A. (ed.) (1995). Manual de mugeres en el qual se contienen muchas y diversas reçeutas muy buenas, Salamanca: Universidad de Salamanca.

Cruz Cruz, J. (2002). Teoría elemental de la Gastronomía. Pamplona: Universidad de Navarra.

Cruz de Amenábar, I. (1989). La cultura escrita en Chile 1650-I820. Revista Historia 24, I07-213.

Cruz de Amenábar, I. (1995). La Fiesta. Metamorfosis de lo cotidiano. Santiago: Ediciones UC. 
Cruz de Amenábar, I. (2003). Dulces agasajos: notas sobre la creación culinaria y su significado en el arte festivo del barroco en Chile. En Barroco Andino. La Paz: Vice-Ministerio de Cultura, $87-94$.

Cruz de Amenábar, I.; Fuentes, A.; de La Taille, A. (2019). Cerámica perfumada de las monjas clarisas: Desde Chile hacia el mundo. Oficio, terapéutica y consumo, siglos XVI-XX. Santiago: Ediciones $\mathrm{UC}$.

(1642). Constituciones generales para todas las monjas y religiosas, sujetas a la obediencia de la Orden de Nuestro Padre San Francisco, en esta familia cismontana. De nuevo recopiladas de las antiguas; $y$ añadidas con acuerdo, consentimiento, y aprobacion del Capitulo General, celebrado en Roma a onze de Julio de 1639. Madrid: Imprenta Real.

Dioscórides. (2007). Plantas I. Madrid: Gredos.

Faraudo de Saint Germain, L. (1946). «Libre de totes maneres de confits»: Un tratado manual cuatrocentista de arte de dulcería. Boletín de la Real Academia de Buenas Letras de Barcelona (19), 97-I34.

Fernández-Armesto, F. (2019). Historia de la comida. Alimentos, cocina y civilización. Buenos Aires: Tusquets.

Fuentes, A. (2019). Entre la oración contemplativa y el trabajo de sus manos: Clausura femenina y prácticas laborales en el Monasterio Antiguo de Santa Clara de Santiago, 1678-1825. Tesis para optar el grado de Doctor en Historia, Universidad de los Andes, Santiago de Chile, inédita.

García-Atance, M. (2002). Barroco Hispanoamericano en Chile. Vida de San Francisco de Asís. Madrid: Ministerio de Educación, Cultura y Deporte.

García Sánchez, E. (1989). El azúcar en la alimentación de los andalusíes. En Actas del Primer Seminario Internacional: La caña de azúcar en tiempos de los grandes descubrimientos (1450-1550). Motril: Casa de la Palma, 2I4-I25.

Henry, N. E; Guibourt, G. (i83o). Farmacopea Razonada o Tratado de Farmacia Práctico y Teórico. Madrid: Imprenta de los Hijos de doña Catalina Piñuela.

Howes, D. (2014). El creciente campo de los estudios sensoriales. Revista Latinoamericana de Estudios sobre Cuerpos, Emociones y Sociedad (6: 15), I0-26.

Korsmeyer, C. (2002). El sentido del gusto. Estética y filosofía. Barcelona: Paidós.

López, M. (1998). La Serie de los cinco Sentidos de Marten de Vos y Adriaen Collaert como fuente iconográfica. Saitabi, Revista de la Facultad de Geografía e Historia (48), 311-333.

Mapelli, E. (2004). Ora et labora. La dulcería monacal de las monjas. En Campos, F. La clausura femenina en España Vol. I. Sevilla: Real Centro Universitario Escorial- María

Cristina, I8I-200. 
Martínez Llopis, M. (1989). Historia de la Gastronomía Española. Madrid: Alianza.

Martínez Llopis, M. (1999). La dulcería española. Recetario histórico y popular. Madrid: Alianza.

Mata, J. (1747). Arte de Repostería, en que se contiene todo genero de hacer dulces secos, y en líquido, vizcochos, turrones, y natas. Madrid: por Antonio Marín.

Mintz, S. (1996). Dulzura y poder. El lugar del azúcar en la historia moederna. México DF.: Siglo XXI editores.

Montecino, S. (2005). La olla deleitosa. Cocinas mestizas de Chile. Santiago: Catalonia.

Mujica, R. (2007). Apuntes sobre moros y turcos en el imaginario andino virreinal. Anuario de Historia de la Iglesia (16), 169-179.

Nola, R. (1997). Libro de guisado, manjares y potajes intitulado libro de cocina, edición impresa en Logroño el año I529. En Cruz Cruz, J. La cocina mediterránea en el inicio del Renacimiento. Huesca: La Val de Onsera, 226-375.

Omaecheverría, I. (1993). Escritos de Santa Clara y documentos complementarios. Madrid: BAC.

Ortiz, L. (1687). Ver, oír, oler, gustar y tocar. Empresas que enseñan, y persuaden su buen uso, en lo político y en lo moral. León: Imprenta de Anisson, Posuel y Rigaud.

Ovalle, A. (1646). Histórica Relación del Reyno de Chile. Roma: Francisco Caballo.

Pereira Salas, E. (1977). Apuntes para la historia de la cocina chilena. Santiago: Universitaria.

Pérez Vidal, J. (I973). La cultura de la Caña de Azúcar en el Levante Español. Madrid: CSIC.

Pérez Samper, M. (2012). Recetarios manuscritos de la España moderna. Cincinnati Romance Review (33), 27-58.

Peña, C. (1951). Una crónica conventual. Las agustinas de Santiago 1574-1951. Santiago: s.e.

RAE. (I726). Diccionario de la lengua castellana, en que se explica el verdadero sentido de las voces, su naturaleza y calidad con las phrases o modos de hablar, los proverbios o refranes, y otras cosas convenientes al uso de la lengua, Tomo I. Madrid: Imprenta de Francisco del Hierro.

Ramón, A.; Larraín, J. (1982). Orígenes de la vida económica chilena, 1659-1808. Santiago: CEP.

Reale, G.; Antiseri, D. (1995). Historia del Pensamiento Filosófico y Científico, Tomo II. Barcelona: Herder.

Riera-Melis, A. (2014). El azúcar en la farmacopea y la alta cocina árabes medievales. En Sabaté i Curull, F. (ed). El sucre en la história: alimentació, quotidianitat i economía. Barcelona: Pages, 4O-4I. 
Riera-Melis, A. (2003). El mediterráneo, crisol de tradiciones alimentarias. El legado islámico en la cocina medieval catalana. En Devroey, J.P. El mundo en la cocina. Historia, identidad, intercambios. Buenos Aires: Paidós, I7-50.

Ritchie, C. (198I). Comida y civilización. Madrid: Alianza.

Rosales, D. (1877). Historia General del Reyno de Chile. Flandes Indiano, Tomo I. Valparaíso: Imprenta del Mercurio.

Rose, K. (1992). El azúcar: usos dietéticos y farmacéuticos según los médicos árabes medievales. En Malpica, A. (ed). 1492: lo dulce a la conquista de Europa: actas del IV Seminario Internacional sobre la caña de azúcar. Motril: Diputación de Granada, 4I-62.

Rubial, A. (20iI). Los cinco sentidos en la experiencia mística femenina novohispana. En Rubial, A.; Bieñko, D. Cuerpo y religión en el México barroco. México D.F.: Instituto Nacional de Antropología de Historia, I45-I82.

Sancho Valls, J., et al (1999). Introducción al análisis sensorial de los alimentos. Barcelona: Ediciones Universitat de Barcelona.

Sciolla, C. (2010). Historia y cultura de la alimentación en Chile. Santiago: Catalonia.

Schneider, N. (2003). Naturaleza muerta. Colonia: Taschen.

Simón, M. (20ro). La dulcería en la Biblioteca Nacional de España. En La cocina en su tinta. Madrid: Biblioteca Nacional de España, 63-8I.

Taboada, H. (2004). El moro en las Indias. Latinoamérica (39), II5- I32.

Toussaint-Samat, M. (1987). Historia natural y moral de los alimentos, Vol. 7: "El azúcar, el chocolate, el café y el té". Madrid: Alianza.

Valdés, R. (1994). Con mano de monja. Los conventos y la cocina colonial. Revista Universitaria (43), $\mathrm{s} / \mathrm{p}$.

Vergel de señores en el qual se muestra a hacer con mucha excelencia todas las conservas, electuarios, confituras, turrones y otras cosas de azucar y miel, c. Siglo XV, manuscrito inédito de la Biblioteca Nacional de España. Disponible en https://cutt.ly/imSVpı

Vial, G. (1957). El africano en el Reino de Chile. Santiago: Instituto de Investigaciones Históricas.

Zolla, C. (1988). Elogio del dulce. Ensayo sobre la dulcería mexicana. México: FCE. 